\title{
The Reflection of Plication Surgery for Diaphragm Eventration to Respiratory Function Test
}

\author{
Serdar Özkan ${ }^{1}$, Ülkü Yazıcı ${ }^{2}$ Ertan Aydın³, Nurettin Karaoğlanoğlu ${ }^{2}$ \\ ${ }^{1}$ Department of Thoracic Surgery, Siirt State Hospital, Siirt, Turkey \\ ${ }^{2}$ Department of Thoracic Surgery, Dışkapı Yıldırım Bayezit Training and Research Hospital, Ankara, Turkey \\ ${ }^{3}$ Department of Thoracic Surgery, Koru Hospitals, Ankara, Turkey
}

To the Editor,

Diaphragm plication surgery is conducted to remove dyspnea, which results from mediastinal shift, atelectasia and ventilation/perfusion dyssynchrony in lungs that occur due to an eventrated diaphragm.

A total of 16 cases that underwent diaphragm plication surgery in our clinic due to eventration or paralysis were examined prospectively. Diaphragm eventration values were calculated by means of a new calculation method through PA pulmonary radiographies taken during patient admission and control.

Using PA pulmonary radiography, the distance between the peak of the intactus hemidiaphragm and apex point of the ipsilateral hemithorax was measured with this new method. Similarly, the distance between the peak of the eventrated hemidiaphragm and the apex point of ipsilateral hemithorax was measured. The ratio of distances and eventration level were calculated by percentage.

Compared to preoperative values, a decrease was found in FEV1 (lt) values of three cases in the first month, four cases in the sixth month and six cases in the twelfth month of postoperative control. Compared to preoperative values, no change was found in FEV1 (lt) values of two cases in the first month, two cases in the sixth month and one case in the twelfth month of postoperative control. Compared to preoperative values, a decrease was found in FVC (1t) values of three cases in the first month, five cases in the sixth month and seven cases in the twelfth month of postoperative control. Compared to preoperative values, no change was found in FVC (1t) values of two cases in first month, one case in the sixth month and one case in the twelfth month of postoperative control (Table 1).

With regard to the plication operation in general, the first investigation for the indication of an operation was made by Svanberg in 1956. Since then, it has been argued whether repair of the diaphragm at the lower levels with plication is functional or not (1). Mulvey et al. (2) followed 12 cases for two to four years and no clear change was found in the spirometric measurements of pulmonary volumes. According to research investigating 17 diaphragm plication cases in a wide and long follow-up period, which was reported at the 2006 EACTS/ESTS congress, it was found that the postoperative mean FEV1 value was $71 \%$, which was an increase from $64 \%$ in the preoperative period (3). In the present study, an increase was found in RFT values in nine $(56.2 \%)$ cases compared to the preoperative values. However, considering that the mean increase was $0.09 \mathrm{lt}$ for FEV1 and $0.13 \mathrm{lt}$ for FVC, it is evident that discussions on the indication of diaphragm plication operation are justified.

We believe that more selective decisions should be taken when determining whether patients are appropriate for surgery in unilateral diaphragm eventrations and especially in the adult patient group; plication operations should not be used for low-level diaphragm eventrations which do not result in mediastinal shift. 
TABLE 1. Comparing values of preoperative and postoperative respiratory function tests and symptomatology at postoperative twelfth month

\begin{tabular}{|c|c|c|c|c|c|c|c|c|c|c|c|c|c|c|c|c|c|c|c|c|c|}
\hline \multirow[b]{3}{*}{ Case } & \multicolumn{5}{|c|}{ Preoperative } & \multicolumn{5}{|c|}{ Postoperative $1^{\text {st }}$ month } & \multicolumn{5}{|c|}{ Postoperative $6^{\text {th }}$ month } & \multicolumn{5}{|c|}{ Postoperative $12^{\text {th }}$ month } & \multirow[b]{3}{*}{ Symp. } \\
\hline & \multicolumn{2}{|c|}{$\mathrm{FEV}_{1}$} & \multicolumn{2}{|c|}{ FVC } & \multirow{2}{*}{$\frac{E}{\%}$} & \multicolumn{2}{|c|}{$\mathrm{FEV}_{1}$} & \multicolumn{2}{|c|}{ FVC } & \multirow{2}{*}{$\frac{\mathrm{E}}{\%}$} & \multicolumn{2}{|c|}{$\mathrm{FEV}_{1}$} & \multicolumn{2}{|c|}{ FVC } & \multirow{2}{*}{$\frac{\mathrm{E}}{\%}$} & \multicolumn{2}{|c|}{$\mathrm{FEV}_{1}$} & \multicolumn{2}{|c|}{ FVC } & \multirow{2}{*}{$\frac{\mathrm{E}}{\%}$} & \\
\hline & lt & $\%$ & 1t & $\%$ & & 1t & $\%$ & 1t & $\%$ & & 1t & $\%$ & $1 \mathrm{t}$ & $\%$ & & 1t & $\%$ & 1t & $\%$ & & \\
\hline 1 & 1.52 & 50 & 2.15 & 56 & 23.8 & 1.64 & 54 & 2.36 & 62 & 15.3 & 1.59 & 53 & 2.54 & 66 & 13.3 & 1.49 & 50 & 2.05 & 53 & 16 & $\mathrm{~S}$ \\
\hline 2 & 1.82 & 77 & 2.22 & 79 & 37.6 & 1.66 & 70 & 1.80 & 64 & 5.7 & 2.34 & 96 & 2.45 & 85 & 20 & 1.91 & 82 & 2.20 & 80 & 21 & S \\
\hline 3 & 2.95 & 77 & 4.17 & 90 & 26.9 & 2.48 & 65 & 3.20 & 69 & 15.7 & 2.32 & 60 & 3.19 & 69 & 15.1 & 2.55 & 68 & 3.46 & 76 & 12.5 & $\mathrm{~S}$ \\
\hline 4 & 1.65 & 54 & 2.18 & 57 & 36 & 1.96 & 65 & 2.68 & 70 & 8.7 & 2.30 & 76 & 3.07 & 81 & 11.1 & 1.95 & 68 & 2.69 & 75 & 13.2 & $\mathrm{~S}$ \\
\hline 5 & 1.59 & 66 & 2.15 & 77 & 34.4 & 1.44 & 58 & 1.68 & 58 & 14.9 & 1.36 & 57 & 1.74 & 62 & 15 & 1.11 & 45 & 1.48 & 51 & 23 & B \\
\hline 6 & 2.46 & 62 & 3.15 & 67 & 33.5 & 2.74 & 68 & 3.15 & 67 & 12.5 & 2.67 & 67 & 3.42 & 73 & 7.8 & 2.43 & 63 & 3.07 & 66 & 14.3 & B \\
\hline 7 & 1.67 & 51 & 2.03 & 50 & 20 & 1.68 & 52 & 2.20 & 54 & -10.7 & 2.45 & 76 & 3.21 & 79 & -8.3 & 2.63 & 83 & 3.17 & 79 & -4.3 & W \\
\hline 8 & 2.13 & 59 & 2.67 & 60 & 31.4 & 2.58 & 70 & 3.07 & 68 & 14.7 & 2.04 & 55 & 2.46 & 54 & 18.8 & 2.01 & 55 & 2.28 & 50 & 18.1 & B \\
\hline 9 & 1.91 & 59 & 2.79 & 68 & 45.6 & 2.21 & 70 & 3.15 & 80 & 0 & 2.40 & 94 & 3.50 & 117 & 4.5 & 2.21 & 74 & 3.04 & 80 & 13.4 & B \\
\hline 10 & 1.05 & 64 & 1.42 & 71 & 50 & 1.16 & 73 & 1.42 & 73 & 36.9 & 1.16 & 71 & 1.43 & 72 & 44.9 & 1.09 & 80 & 1.15 & 68 & 33.5 & S \\
\hline 11 & 2.13 & 66 & 2.66 & 67 & 32.6 & 2.23 & 69 & 2.70 & 68 & 13.7 & 2.17 & 67 & 2.56 & 64 & 15.1 & 2.42 & 79 & 3.12 & 83 & 13.1 & B \\
\hline 12 & 2.13 & 60 & 2.52 & 57 & 26 & 2.87 & 82 & 3.20 & 70 & -11.1 & 2.78 & 79 & 3.16 & 73 & -16.7 & 2.45 & 72 & 2.77 & 65 & -5.7 & W \\
\hline 13 & 2.12 & 55 & 2.28 & 50 & 34.6 & 2.58 & 68 & 2.86 & 63 & 11.2 & 2.46 & 64 & 2.71 & 59 & 12.3 & 2.30 & 62 & 2.65 & 57 & 15.2 & B \\
\hline 14 & 1.61 & 47 & 2.29 & 55 & 18.7 & 1.89 & 55 & 2.52 & 61 & -7.4 & 1.92 & 58 & 2.71 & 64 & -5.3 & 1.85 & 56 & 2.63 & 63 & 0 & $\mathrm{~S}$ \\
\hline 15 & 1.93 & 62 & 2.60 & 67 & 23.5 & 1.98 & 63 & 2.90 & 74 & 5.6 & 2.24 & 74 & 3.58 & 96 & 4.9 & 2.38 & 77 & 3.72 & 94 & 5.2 & B \\
\hline 16 & 1.31 & 58 & 1.44 & 55 & 23.5 & 1.42 & 63 & 1.57 & 59 & 2.9 & 1.12 & 46 & 1.14 & 40 & 1.4 & 1.21 & 51 & 1.35 & 43 & 1.9 & W \\
\hline Mean & 1.87 & 60.4 & 2.42 & 64.1 & 31.1 & 2.03 & 65.3 & 2.51 & 66.2 & 8.03 & 2.08 & 68.3 & 2.67 & 72.1 & 9.6 & 1.99 & 66.5 & 2.55 & 67.6 & 11.9 & \\
\hline
\end{tabular}

B: better; E: eventration; S: same; Symp: symptom; W: worse

Ethics Committee Approval: Ethics committee approval was received for this study from the ethics committee of Atatürk Training and Research Hospital for Chest Disease and Chest Surgery.

Informed Consent: Written informed consent was obtained from patients who participated in this study.

Peer-review: Externally peer-reviewed.

Author contributions: Concept - S.Ö.; Design - Ü.Y.; Supervision - Ü.Y., E.A.; Resource - S.Ö.; Materials - S.Ö.; Data Collection \&/or Processing - E.A.; Analysis \&/or Interpretation - S.Ö.; Literature Search - S.Ö.; Writing - S.Ö.; Critical Reviews - N.K.

Conflict of Interest: No conflict of interest was declared by the authors.
Financial Disclosure: The authors declared that this study has received no financial support.

\section{REFERENCES}

1. Svanberg L. Clinical value of analysis lung function in some intrathoracic diseases: Spirometric, bronchospirometric and angiopneumographic investigation. Acta Chir Scand 1956;111:169-96.

2. Mulvey AD, Aquilina RJ, Elliott MW, Moxham J, Green M. Diaphragmatic dysfunction in neuralgic amyotrophy: an electrophysiologic evaluation of 16 patients presenting with dyspnea. Am Rev Respir Dis 1993;147:66-71. [CrossRef]

3. Versteegh MI, Braun J, Voigt PG, Bosman DB, Stolk J, Rabe KF, et al. Diaphragm plication in adult patients with diaphragm paralysis leads to longterm improvement of pulmonary function and level of dyspnea. Eur J Cardiothorac Surg 2007;32:449-56. [CrossRef] 